\title{
Chondroid Syringoma of the Hypothenar Region
}

\author{
Fatma Markoç ${ }^{1}$, Bora Bostan ${ }^{2}$, R. Doğan Köseoğlu ${ }^{1}$, A. Burcu Arıkan ${ }^{1}$, Murat Aşc1 ${ }^{2}$ \\ ${ }^{1}$ Department of Pathology, Gaziosmanpaşa University School of Medicine, Tokat, Turkey \\ ${ }^{2}$ Department of Orthopedics and Traumatology, Gaziosmanpaşa University School of Medicine, Tokat, Turkey
}

To the Editor,

Chondroid syringoma (CS) is a benign adnexal tumor of eccrine/apocrine sweat glands. CS constitutes of $0.01-0.1 \%$ of primary skin tumors (1). CS is usually seen in elderly males as a painless, slowly growing, well demarcated subcutaneous/ intradermal nodular lesion originating from the skin of the region of the head and neck, especially the cheek, nose and lip (2). Rare localization areas are the axillary region, abdomen, trunk, genitalia and extremities $(1,2)$. There are a few case reports defining the cytological characteristics of CS in the English language literature (2-5).

A 30 year-old female patient was admitted because of a slowly growing painless swelling in the right hypothenar region for 5 years (Figure 1). The swelling was in a character of well demarcated subcutaneous nodular lesion. Aspiration smears had moderate cellularity with mild nuclear pleomorphism. Single or small groups of tumor cells with slightly eccentric nuclei on chondromyxoid matrix were noticed (Figure 2). The cytological findings reminded benign mixed tumor of salivary glands. We reported the case as a benign tumoral lesion with chondroid matrix. The excised lesion was a well demarcated and partially capsulated nodular lesion with bright, solid gray-white colored cut-section. The lesion had dimensions of $2.5 \times 2 \times 1.5 \mathrm{~cm}$. Microscopy showed an intradermal/subcutaneous tumoral lesion consisting of small clusters or short chords of benign epithelial or myoepithelial cells in chondromyxoid matrix. There were no findings of necrosis, atypical mitoses, meaningful nuclear pleomorphism and vascular invasion. We diagnosed CS on the basis of the histopathological findings. No recurrence was observed 3 years after the excision. Informed consent was obtained from the patient.

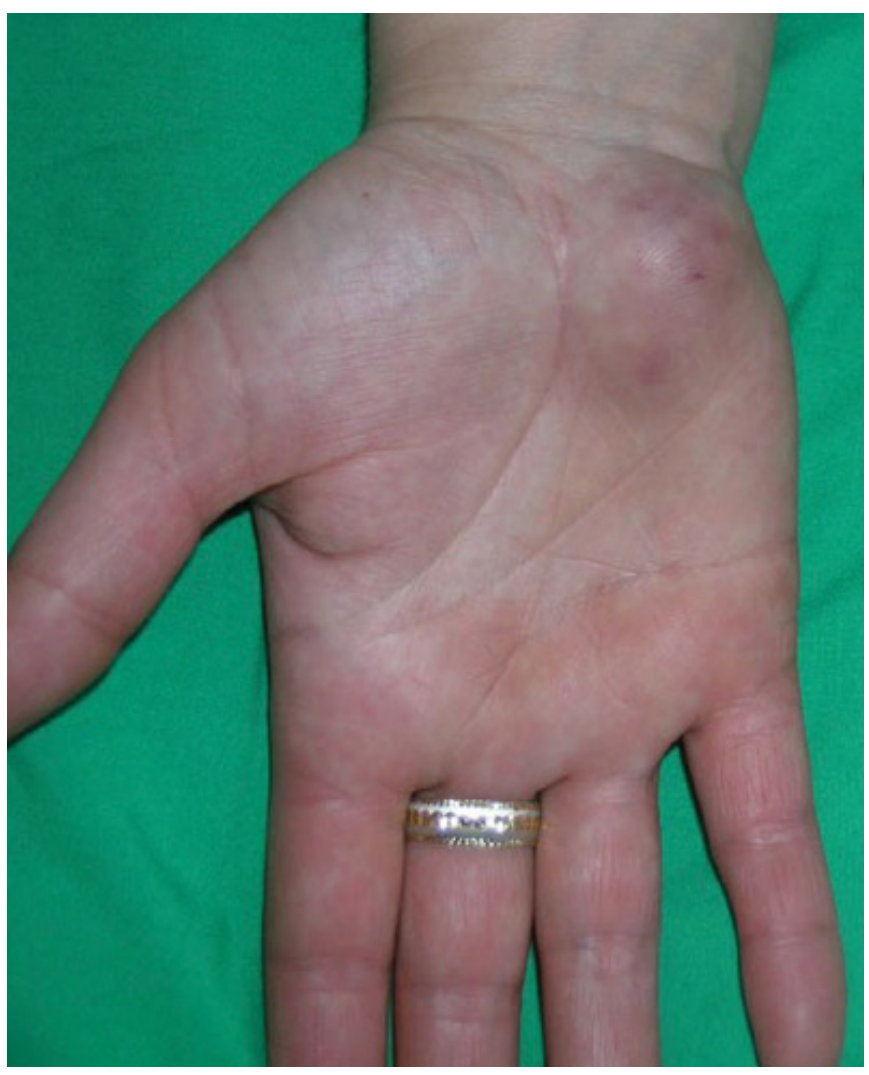

FIG. 1. A subcutaneous nodular lesion with overlying intact skin on right hypothenar region

Despite CS usually being benign tumors, malignant forms have been also reported $(1,2)$. Malignant forms usually localize on the trunk and extremities and are mostly seen in young women. They are rapidly growing masses and their diameters are larger than $3 \mathrm{~cm}$. Erosion/ulceration of the overlying skin is frequent. Mortality rates are high due to metastasis to the

This study was presented as a poster presentation at the $20^{\text {th }}$ National Congress of Pathology, 2010, Eskisehir, Turkey.

Address for Correspondence: Dr. R. Doğan Köseoğlu, Department of Pathology, Gaziosmanpaşa University Faculty of Medicine, Tokat, Turkey Phone: +905335789419 e-mail: residdogan@hotmail.com

Received: 24 January 2015 Accepted: 12 May 2015 •DOI: 10.5152/balkanmedj.2015.151027

Available at www.balkanmedicaljournal.org 


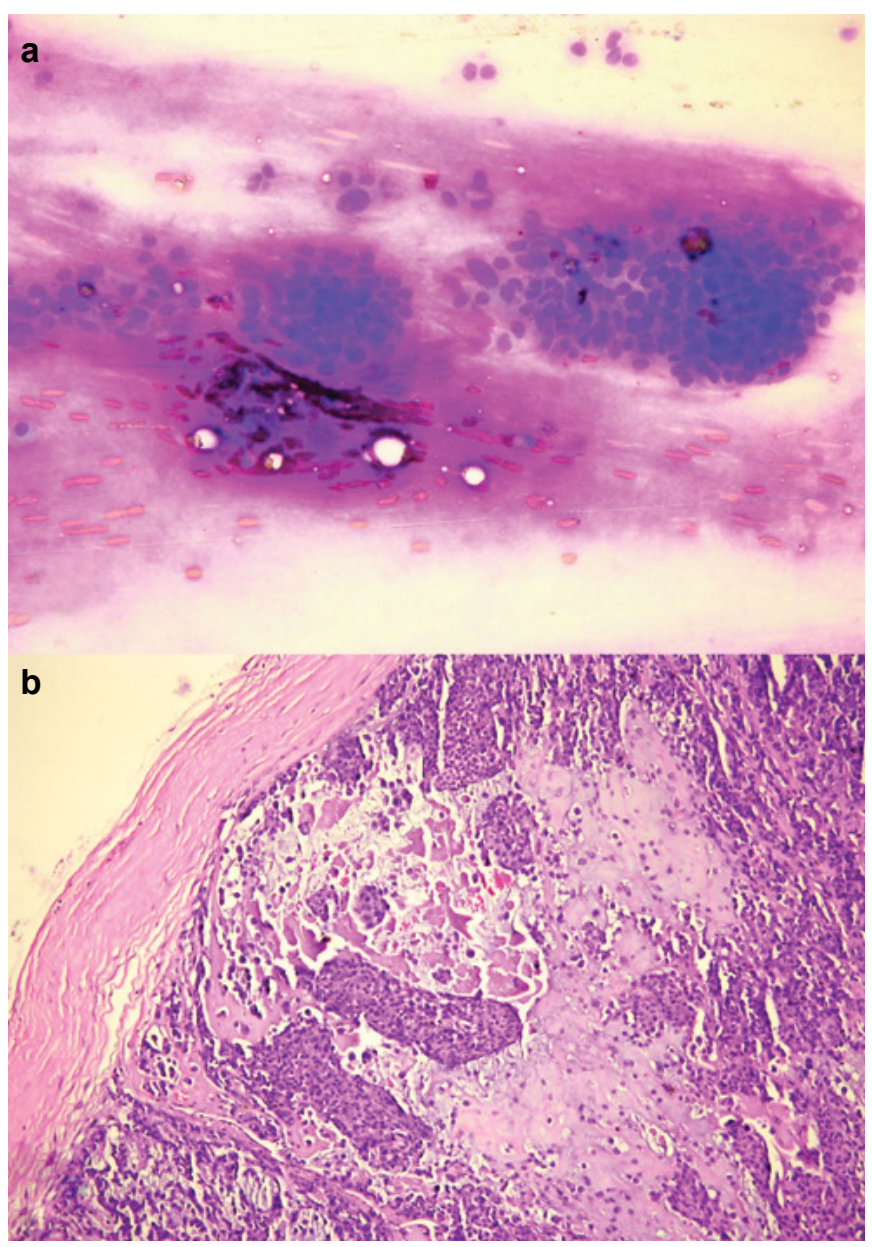

FIG. 2. a, b. Groups of the cells with monomorphic and mildly eccentric nuclei, amphophilic staining cytoplasm in chondromyxoid stroma on aspiration smears (MGG, x20) (a), tumor cell cords and groups intermingled with myxoid stroma (HE, x15) (b)

lung in malignant forms. Histological evidences of malignancy and satellite nodules favor the diagnosis of malignant CS $(1,2)$.

Chondroid syringoma should be differentiated from other subcutaneous tumoral lesions. Some of these lesions are dermoid cysts, sebaceous cysts, peripheral nerve sheet tumors (PNST), lipoma, hemangioma, dermatofibroma and pilomatrixoma, myxoid liposarcoma, extraskeletal myxoid chondrosarcoma, myxofibrosarcoma and malignant PNST $(1,2)$.

The diagnosis is usually made by histopathological examination. However, there are only a few reports describing the cytological characteristics of CS (2-5). The presence of uniform plasmacytoid cells and myoepithelial cells in the chondromyxoid matrix favor the cytological diagnosis of CS (2). These findings may also be seen on aspiration smears obtained from mesenchymal tumors, especially chondroid tissue tumors. Cytological discrimination between malignant CS and sarcomas is very difficult.

The age of our case and localization of the mass were not usual for benign CS. However, there were no histological/cytological and clinical evidences of malignancy. Some cases may be overlooked in routine practice. Hence, if aspiration smears from a subcutaneous nodular lesion show plasmacytoid cells in a chondromyxoid matrix, CS should be considered in the spectrum of differential diagnosis.

\section{Ethics Committee Approval: N/A.}

Informed Consent: Written informed consent was obtained from the patient who participated in this study.

Peer-review: Externally peer-reviewed.

Author contributions: Concept - R.D.K.; Design - R.D.K.; Supervision - F.M., R.D.K.; Resource - B.B.; Materials - B.B.; Data Collection \&/or Processing - B.B., M.A., A.B.A.; Analysis \&/or Interpretation - R.D.K., F.M.; Literature Search - M.A., A.B.A.; Writing - R.D.K., F.M.; Critical Reviews - F.M., B.B., R.D.K., A.B.A., M.A.

Conflict of Interest: No conflict of interest was declared by the authors.

Financial Disclosure: The authors declared that this study has received no financial support.

\section{REFERENCES}

1. Kakitsubato Y, Theodorou SJ, Theodorou DJ, Nakahara M, Yuki Y, Yokouchi T. Giant chondroid syringoma presenting as a growing subcutaneous mass in the upper arm: MRI findings with pathologic correlation. Joint Bone Spine 2009;76:711-4. [CrossRef]

2. Kumar B. Chondroid syringoma diagnosed by fine needle aspiration cytology. Diagn Cytopathol 2010;38:38-40.

3. Kumar S, Ghotekar LH, Thappa DM, Smile R. Diagnosis of chondroid syringoma by FNAC. Acta Cytol 2003;47:522-4.

4. Masood S, Hardy NM. Fine needle aspiration cytology of chondroid syringoma: Report of a case. Acta Cytol 1988;32:482-4.

5. Gottschalk-Sabag S, Glick T. Chondroid syringoma diagnosed by fine needle aspiration: A case report. Diagn Cytopathol 1994;10:152-5. [CrossRef] 